\title{
O sentido objetivo da prática administrativa
}

\section{The objective meaning of management practice}

\author{
Paulo Tromboni Nascimento
}

\begin{abstract}
Resumo
Este artigo examina o sentido da prática administrativa e defende a tese de que é objetivo. A discussão busca a caracterização geral do objeto de investigação. No lugar do objeto das ciências da natureza, inanimado e isolado do sujeito, entra a prática administrativa com sentido objetivo derivado da lógica da situação objetiva do administrador no contexto organizacional. Vale dizer derivado dos propósitos, da rede estruturada de relações sociais e do sistema de práticas da organização. 0 que torna real a sua axiologia referenciada na eficiência e eficácia da ação, além de fazer da prática administrativa um fator de regulação e mudança controlada da organização. Examinar cientificamente uma prática é criar as condições para mudá-la via uma dialética da descrição, explicação e prescrição. A filosofia da prática é proposta como pressuposto geral da pesquisa científica em administração.
\end{abstract}

Palavras-chave: pesquisa da prática; lógica da situação organizacional; filosofia da administração

\begin{abstract}
This article searches through the sense of administrative practice and holds that it is objective. A philosophy of praxis was held here to be the main assumption of management research. The discussion is based on the characterization of the research matter. In the place of the natural sciences subject matter, inanimate and independent from men' will, comes in the management practice with an objective meaning in the organizational context. This objective meaning is the result of the logic of the administrator's objective situation. Which means, of course, the organization's purposes, structured net of social relations and system of management and organizational practices. And this turns the management practice axiology into something real and linked to its efficiency and effectiveness. And so management practice becomes a factor for the regulation and controlled change of organizations. To look scientifically at a practice is to create the conditions under which it will change through a description, explanation and prescription dialectics.
\end{abstract}

Keywords: practices research; organizational situation logic; philosophy of management

\section{Introdução}

Este artigo examina o sentido da prática administrativa e defende a tese de que é objetivo, do mesmo modo que o sentido das palavras independe da subjetividade de quem fala uma língua, ou da mesma forma que uma transação de compra e venda tem um sentido objetivo que se sobrepõe às intenções subjetivas dos participantes.

A filosofia da pesquisa em administração exige tratar da filosofia das ciências sociais. Aqui, filosofia da ciência é uma especulação racional (RUSSEL, 1945, p.xiii) sobre problemas filosóficos com origem na ciência (POPPER, 2002, cap.2). A filosofia auxilia a ciência na conceituação das teorias. Dela se espera que incorpore e critique os avanços científicos.

1 Doutor em Administração pela Faculdade de Economia,Administração e Contabilidade da Universidade de São Paulo.Professor da Faculdade de Economia, Administração e Contabilidade - FEA - Universidade de São Paulo - USP - Endereço: Av. Prof. Dr. Luciano Gualberto, 908, sl. E 111 - Cidade Universitária - São Paulo - SP - Brasil - CEP 05508-900 - E-mail: tromboni@usp.br 
O tema exige distinguir ciência de razão prática. É o que fez Giddens (1993, p.2) ao elaborar a idéia da dupla hermenêutica nas ciências sociais. $O$ autor faz aí menção ao fato de que o cientista da sociedade, diferentemente do da natureza, reflete sobre a prática de sujeitos que pensam para agir. E Giddens (2003) sofistica essa análise da consciência na ação ao distinguir a consciência prática da discursiva. A segunda trata do conhecimento que os atores sabem expressar verbalmente sobre as condições sociais da ação. Já a consciência prática se refere ao seu conhecimento tácito dessas condições, mas não se trata de inconsciente. Não há barreira psicológica impedindo sua explicitação (GIDDENS, 2003, p.440).

A razão prática é parte do objeto da filosofia e das ciências da prática, ou como diz Bhaskar (2004, p.xvii) "o objeto de estudo social inclui as crenças a seu respeito". Assim, o sentido é parte do objeto examinado, a prática administrativa.

\section{A filosofia da prática}

Imitando a terminologia de Bourdieu (1983, p.46), pode-se separar em três grandes campos as posições filosóficas sobre as ciências sociais: fenomenologia (ou subjetivismo), objetivismo e praxiologia. A praxiologia é uma tentativa de superar as duas anteriores, numa síntese mais ampla. Essa síntese é baseada na singela lembrança de que o homem age guiado por sua mente num mundo social e físico que é, em grande parte, criado pelas interações da prática individual e coletiva, mas que foge ao controle dos indivíduos.

Em Vico (1999) surgiu pela primeira vez a idéia de que fazer algo é a condição para conhecer esse algo. Russel (2001, p. 298) lembra que Vico

sustentou que a matemática era perfeitamente cognoscivel por ser feita pelo homem e não se referir à realidade. A natureza não era perfeitamente cognoscivel por ser feita por Deus, mas efetivamente se referir ao real... Vico tentou descobrir uma nova ciência, que ao mesmo tempo fosse perfeitamente cognoscivel e se referisse ao mundo real. Encontrou-a na história, onde o homem e Deus colaboram, numa surpreendente inversão do ponto de vista tradicional, pois os cartesianos haviam banido a história como não científica.

Para Vazquez (1977, p.153), "Marx formula uma concepção do objeto como produto da atividade subjetiva, mas entendida não mais abstratamente, e sim como atividade real, objetiva, material". Ele acrescenta

A práxis aparecerá como fundamento (Tese I contra Feurbach), critério de verdade (Tese II contra Feurbach) e finalidade do conhecimento (Tese XI contra Feurbach) [...] A intervenção da práxis no processo de conhecimento leva à superação da antitese entre idealismo e materialismo, entre a concepção do conhecimento, como conhecimento de objetos produzidos ou criados pela consciência, $e$ a concepção que vê no conhecimento uma simples reprodução ideal de objetos em si..." (VAZQUEZ, 1977, p.149)

Do idealismo, essa concepção baseada na prática preserva o lado ativo e criativo do sujeito no conhecimento e na produção e reprodução efetiva do mundo material e social que o cerca. Do materialismo, essa concepção preserva a noção de independência e anterioridade ontológica desse mundo material e social. Ou como coloca Marx (1976, p.17), "Os homens fazem sua própria história, mas não a fazem arbitrariamente, nas condições escolhidas por eles, mas sim nas condições diretamente determinadas ou herdadas do passado".

Embora ciente do conteúdo mental da prática, Marx enfatiza suas condicionantes materiais e sociais. Por sua vez, as condicionantes sociais seriam influenciadas pelas condicionantes materiais - biológicas, ambientais e produtivas. Por isso, Marx salienta o estudo da economia política, onde a satisfação das necessidades e as restrições materiais à ação humana estão em maior destaque e criam uma rede estrutural de relações sociais - as relações de produção - sobre a qual repousaria o resto do edifício das relações sociais e ideologias. Pode-se tornar absoluta a influência dessas relações de produção e chegar a uma concepção que estabelece a determinação de todas as ideologias pela infra-estrutura, um estruturalismo radical, na caracterização de Burrell 
e Morgan (1979). Independente dessa ênfase geral, no entanto, ninguém negará que escassez de recursos e custos, concorrência e monopólio, propriedade e empregados, lucros e salários e eficiência e eficácia são noções essenciais ao estudo das práticas administrativas, que condicionam fortemente seu sentido.

Sem negar objetividade às situações sociais e materiais, Weber (2004) realça e explora o lado mental da prática. Para Weber é essencial combater a reificação (coisificação) das estruturas sociais, que lhes atribui uma realidade independente da ação e das idéias dos homens. Para isso, ele enfatiza uma visão que se assenta no sentido da ação social. Na tipologia da ação social de Weber há a ação racional em relação a objetivos ou a valores e as ações afetivas e tradicionais. A ação social, em geral, consiste sempre numa combinação desses tipos ideais. Para esse trabalho, o que importa é que a ação social racional é instrumental em relação aos objetivos do agente e às circunstâncias materiais e sociais da ação. Ou seja, as condições objetivas são consideradas pelo agente que escolhe racionalmente o que fazer.

Preocupado com o poder, Weber realça a liberdade humana para politicamente deliberar como agir e trata de explicar como o poder constrange a liberdade de ação dos outros. Independente do real grau de liberdade para agir, a ninguém ocorrerá negar que o processo decisório é o espaço no qual se exerce a liberdade possível de decisão e ação, e que também é o espaço no qual se manifesta a divergência de interesses e concepções.

No nosso caso, preocupados com a prática administrativa como objeto de pesquisa, as duas perspectivas, a marxista e a weberiana, precisam ser consideradas. Não para aprofundar o debate sobre distinções metodológicas ou buscar uma conciliação eclética. O ponto aqui é tentar olhar a prática administrativa tal como ela é, motivada e orientada pelas idéias dos administradores e condicionada por relações sociais e organizacionais e por restrições materiais. Ou seja, os homens têm idéias e elas são essenciais à compreensão das suas práticas administrativas. Além do mais, as práticas administrativas mais eficazes e eficientes vêm acompanhadas de intensa reflexão de teóricos e praticantes para estabelecer seus objetivos, suas condições de aplicação e sua metodologia.

\section{Restrições e liberdade na prática}

O homem precisa agir para viver - buscar comida e abrigo, reproduzir a espécie, ganhar dinheiro. Na prática, o indivíduo se depara com as resistências postas pela realidade física, que não se molda a qualquer ação arbitrária, e com o apoio ou a oposição dos outros membros do seu grupo e sociedade. O pensamento humano, ao cogitar a ação, da mesma forma, enfrenta as limitações que o mundo material e social impõem a essa ação. Isso exige o reconhecimento do objeto - aquilo que se opõe à ação. Objetos e idéias, dos quais dependemos desde que nascemos e com os quais aprendemos até a falar, só funcionam se guardarem alguma relação eficaz com a realidade na qual serão usados.

Além das restrições físicas que é obrigada a respeitar, ${ }^{2}$ a prática se depara com os estímulos e oposições sociais. Grande parte das restrições sociais é internalizada, através de processos de socialização, de maneira que só de modo relativamente pouco freqüente se manifesta abertamente. Mas basta apreciar o que a sociedade faz com quem rouba ou mata para perceber que a sanção social pode ser muito dura, começando por manifestar desaprovação, passando por subtrair a sua cooperação, continuando por restringir as liberdades de ação e participação em grupos e chegando à eliminação pura e simples do recalcitrante, pela morte ou exclusão.

A necessidade de cooperação ${ }^{3}$ estabelece para o indivíduo a necessidade de obter a concordância dos outros membros do grupo, para o que deverá exibir comportamento aceito por eles. Para satisfazer suas necessidades e desejos, o sujeito precisa agir de modo legítimo, aceito pelos outros membros dos grupos e da sociedade que integra.

Nas sociedades complexas, a crescente divisão do trabalho - com a separação e concentração do poder decisório - condiciona a ação individual. De um lado, ela aumenta o alcance potencial da prática se o indivíduo consegue engajar a cooperação de outras pessoas e de organizações. De outro, limita drasticamente o alcance das ações do individuo. A satisfação da mais elementar necessidade individual depende de imensa rede de 
atividades de outros indivíduos e organizações especializados. Giddens $(1993,2003)$ vê aqui a imbricação da ação com o poder, lembrando que o poder não é apenas limitador, mas também habilitador da ação. Isso coloca limites rigorosos aos fins individuais, não compartilhados, exceto os de caráter estritamente subjetivo, como o alcançar a iluminação ascética, por exemplo.

No campo das idéias, entretanto, a liberdade é maior. A imaginação pode ter livre curso, limitada por duas restrições sociais. Primeiro, estão os limites estabelecidos à liberdade de expressão pela sociedade. Há sanções sociais contra idéias consideradas demasiado extravagantes ou perniciosas. A propaganda do nazismo nas modernas sociedades democráticas, por exemplo, é objeto de severa repreensão social e de exclusão das pessoas de meios sociais relevantes para os indivíduos. Representar o sexo em sociedades islâmicas conservadoras também traz estigma social e punição penal.

Mas há outro tipo de restrição social ao pensar, mais sutil e mais profunda. Decorre da socialização e da educação. A pessoa não surge no mundo adulta, já competente no uso de uma linguagem, dominando todo o conhecimento humano, ciente dos valores que pretende obedecer e dotada de um repertório completo de práticas. Pelo contrário, linguagem, conhecimento, valores e práticas são adquiridos no seio de grupos que vão se expandindo conforme o indivíduo atravessa sua infância, adolescência, juventude, maturidade e velhice. Tudo isso ele assimila de modo mais ou menos acrítico. Assim, a liberdade de pensar é fortemente condicionada por essa herança cultural, que é um produto social e precisa ser reproduzida por e para cada novo sujeito que se apresenta ao grupo social. Esse condicionamento, como frisa Giddens (1993, 2003), é tanto restritivo quanto habilitador do pensamento e da imaginação, além de estabelece a base cognitiva e valorativa para a formulação e deliberação de cursos de ação pelos indivíduos.

Mesmo sem negar o livre arbítrio para o pensamento e a tomada de decisões, é possível, portanto, encontrar grande objetividade na subjetividade das pessoas. Elas pensam e agem de modo similar porque convivem num meio que estabelece restrições sociais e materiais, em grande parte, comuns para todos, bem como outras tantas, comuns apenas para determinados grupos ${ }^{4}$ sociais. Para perseguir com eficácia seus objetivos livremente assumidos, quase sempre escolhidos dentre um leque padronizado, o indivíduo precisa agir levando em conta tais restrições; do contrário, não consegue nada. Vez ou outra alguém inova e cria novos objetivos e métodos, algo raro e importante, por servir de base ao progresso da prática.

\section{A prática organizada e a administrativa}

Quando se fala em prática, é preciso distinguir a ação individual da coletiva. A segunda é aquela que o indivíduo não consegue realizar sozinho (carregar um caixão, por exemplo), ou que só faz sentido no contexto de uma divisão de trabalho, na qual um conjunto de ações diferenciadas produz um resultado (no exemplo clássico de Adam Smith, cortar o fio não tem sentido isoladamente, mas só no contexto da fabricação de alfinetes). Pode ser o caso ainda de ações encadeadas com dependência, como a feitura do desenho da peça como premissa para o trabalho do operário.

É evidente que as práticas coletivas têm finalidade e adquirem sentido num contexto social, no qual sua realização encontra também os meios necessários e as situações que as tornam úteis. Portanto, são entes teleológicos cuja causa está na finalidade a que servem, sempre que alguma situação tipificada previamente as torna convenientes ou necessárias. Não há metafísica nessa teleologia. A concepção teleológica de uma prática decorre tão somente de seu uso funcional - serve para algo -, bem como de sua repetição e aperfeiçoamento com a retroalimentação do desempenho efetivo.

Cook e Brown (1999, p.386) atribuem à expressão "prática" o significado de "as atividades coordenadas de indivíduos ou grupos quando fazem o seu trabalho como lhes é ditado pelo seu particular contexto grupal ou organizacional ". ${ }^{5}$ Os dois autores distinguem prática, comportamento e ação. Para eles "comportamento" refere-se a fazer algo, enquanto "ação" refere-se a fazer algo imbuído de sentido. "Prática" seria a ação com significado referido a uma organização ou grupo. 
Para os fins desse artigo interessa focar o contexto organizacional, e nele é preciso ainda distinguir a prática operacional da administrativa. A primeira se refere às ações coletivas para realizar a "missão organizacional" (com o sentido de Simon, de serviços prestados pela empresa).

$\mathrm{Na}$ fórmula clássica de Fayol, administrar é prever, organizar, comandar, coordenar e controlar a ação de um grupo com objetivos coletivos. Aqui, propõe-se entender "prática administrativa" como seqüêencias de ações articuladas dos administradores, com sentido objetivo no contexto organizacional, para organizar, planejar, dirigir e controlar as práticas (o trabalho e as rotinas) das pessoas administradas.

\section{0 sistema de práticas organizacionais}

Receitas e lucros resumem os objetivos de negócios, mas sozinhos não definem o propósito organizacional. Este necessita ser definido em conexão íntima com as atividades efetivamente realizadas pela organização. É a idéia de missão. Ninguém imagina que uma empresa automobilística viva sem receitas e lucros, mas é evidente que sua receita e lucros provêm da fabricação e venda de automóveis. Sua missão é produzir automóveis para o público. Essa distinção é importante porque a administração da organização depende da definição adotada de sua missão. Os objetivos de negócio são sempre similares, mas as missões mudam a cada organização! Para o investidor financeiro, todos os negócios consomem capitais e oferecem lucros baseados nas vendas realizadas. Numa primeira apreciação de distintas oportunidades, ele até pode abstrair a missão da organização. Entretanto, o conhecimento da missão organizacional é vital para administrar a organização, por que dela dependem diretamente os produtos da organização e, através deles, toda a divisão de trabalho e as rotinas de ação, solução de problemas ou tomada de decisões.

Com a definição da missão e dos produtos da organização nasce um critério para a definição do trabalho necessário. A próxima etapa é determinar quais as atividades necessárias e como devem ser ordenadas (divididas, seqüenciadas, articuladas entre si, padronizadas e realizadas; numa palavra, organizadas) para produzir os produtos e cumprir as missões da organização. A seleção dessas atividades, em geral, busca as que já são realizadas na sociedade e/ou em outras organizações. Em geral, são atividades rotineiras, seja por razões profissionais, seja por razões de mercado. Não se exclui, entretanto, em casos específicos, que haja necessidade de alterar rotinas ou até criar novas práticas para uma ou outra etapa ou atividade do processo operacional. Aliás, boa parte do esforço competitivo é de alteração ou invenção de práticas de melhor desempenho.

O próximo passo é estimar os recursos físicos, humanos e financeiros necessários. Nesse ponto, há necessidade de implantar a estrutura organizacional, seja em termos de divisão dos recursos, da melhor forma considerada pelos organizadores das atividades, seja para definir a estrutura de coordenação, sem a qual o funcionamento regular da divisão de trabalho não aconteceria.

Ressalve-se aqui que a forma teleológica da exposição anterior não é necessariamente descritiva de como nasceram as primeiras organizações, nem esgota todo o processo de criação de organizações no mundo contemporâneo. Sempre há um componente maior ou menor de adaptação espontânea no processo de criação e desenvolvimento de uma organização. Entretanto, isso não quer dizer, seja lá como for que se estabeleça a estrutura de atividades da organização, que a coordenação das rotinas e práticas possa ser evitada. Se cada atividade não tiver condições previamente estabelecidas para começar e resultados esperados definidos, logo se instalará o caos e a organização se converterá em desorganização, impedindo a realização das missões organizacionais. Assim, se as rotinas não se articulam entre si de modo instrumental, a organização desmorona e nada produz. Vale dizer que cada rotina ou prática depende das práticas que a antecedem e fornece resultados para as que a sucedem, além do fato de que deve acontecer no momento certo. A implantação de um telhado depende da construção de uma estrutura que o apóie ou de uma atividade que o tire pronto do chão e o coloque no topo da obra!

Por isso, onde há divisão de trabalho, as práticas e rotinas não são arbitrárias e sujeitas à vontade individual. Elas fazem parte de um conjunto organizado de práticas. Podem recorrer a certos recursos e entradas e devem fornecer certos resultados no tempo adequado. Devem obedecer a um programa prévio ou acontecer quando 
solicitadas. Embora o sistema tolere incoerência, em algum nível, essa tolerância esbarra no limite da desorganização quando o sistema não consegue cumprir mais sua missão.

O sistema de atividades da organização inclui um subsistema operacional e um administrativo. Para fins deste artigo, podemos denominar as práticas e rotinas que integram o subsistema administrativo de Sistema de Práticas Administrativas.

\section{A reprodução e mudança controlada da prática organizada}

Processos, sistemas e estruturas administrativos não existem de per si, qual ideal platônico acima do mundo real. Mesmo podendo serem materializados em documentos que lhes dão objetividade (POPPER, 1979), são, ao contrário, realidades constantemente recriadas e modificadas na prática das pessoas que participam das organizações ou com elas interagem.

Nelson e Winter (1982, p.14) caracterizam a empresa por suas rotinas.

Recorremos ao termo geral "rotina" para designar todos os padrões comportamentais previsíveis e regulares das firmas. O termo inclui as características das firmas que alcançam desde rotinas bem especificadas para produzir, passando por procedimentos de contratação, demissão, reposição de estoques, ou aumento de produção de itens com demanda em crescimento, até políticas relacionadas a investimento, pesquisa e desenvolvimento, ou propaganda, e estratégias de negócios para diversificação do produto e investimentos no exterior6.

Nesse ponto, convém lembrar com Mingers (2000, p.1263) que "em contraposição às leis do mundo físico, que não são afetadas pela sua própria operação, as relações e estruturas sociais não existem de forma independente das atividades que as realizam." É por meio dessas atividades que as estruturas sociais se reproduzem inalteradas ou se modificam.

Acompanhar Durkheim (RODRIGUES, 2004, p.52) e tratar o fato social como coisa leva à reificação dos processos sociais e a sociedade como fenômeno independente da ação de seus integrantes.7 As práticas não existem como uma coisa. Existem somente quando evocadas e repetidas como relações e ações em processos. A repetição ou reprodução, entretanto, não deve ser entendida como periodicidade, alta freqüência ou exatidão. Lembra Giddens (1993, p.134), que cada reprodução é uma nova produção que pode diferir da versão anterior!

As práticas podem ser, por elas próprias, periódicas, como acontece quando da confecção da folha de pagamentos. Ou podem resultar da emergência periódica de determinadas condições de aplicação: como ocorre quando, na véspera dos finais de ano, as lojas precisam contratar vendedores temporários para atender à demanda. Mas também podem ser reaplicadas somente quando condições adequadas estão presentes. Por exemplo, quando a saída de um empregado leva a necessidade de preenchimento da vaga.

Por outro lado, uma prática pode ser esporádica; como quando é preciso contratar um presidente via, por exemplo, uma empresa de head hunters. A prática aqui não é rotina da organização que contrata. Mas é rotina da empresa contratada.

A repetição de uma prática não supõe que garanta sempre um resultado correto e confiável, como é o caso, por exemplo, de um algoritmo de solução analítica de uma equação matemática. Basta que seja uma heurística. Reaplicada, pode resultar em outra solução. Assim, quando um anúncio de vaga não trouxer candidatos satisfatórios, sua republicação quase certamente resultará em outro grupo de candidatos.

Em conseqüência, não se pretende que uma prática tenha necessariamente uma definição absolutamente rigorosa. Como numa receita de cozinha, muitas vezes, certos detalhes são deixados em aberto, à discrição do praticante. Outros, não são claros, principalmente, no começo do uso de uma prática. Algumas das condições para o sucesso de uma prática podem ser desconhecidas inicialmente e somente com o uso repetido, elas se 
tornam evidentes e são incorporadas. É quase ocioso lembrar que uma prática não oferece necessariamente uma solução ótima.

Assim, a noção de prática administrativa não precisa ser vista necessariamente como uma rotina precisamente definida, mas como um procedimento fluído - nem sempre completamente definido - e aberto a evoluir conforme aumente o conhecimento de seus aplicadores ou mudem as circunstâncias de sua aplicação. Pode tornar-se obsoleto e ser abandonado, e podem surgir novas práticas administrativas.

Prática aqui pode ser um procedimento de rotina de uma organização ou de uma profissão. Mas não é necessário cingir a prática às rotinas. Uma parte importante da prática administrativa é justamente enfrentar e resolver novos problemas, tomar decisões e redefinir práticas. March e Simon (1958, cap.7) já frisaram esse componente inovador no planejamento - a elaboração de novos programas. Mintzberg (1980) dá um passo adiante, ao sugerir que administração ainda é uma arte que tem uma parte não programável.

A evolução constante das práticas acarreta que o objeto de estudo da administração está em constante evolução e numa escala de tempo relativamente curta. Assim é que o modelo de gestão industrial fordista, que se difundiu triunfante por todo o século passado, em menos de 20 anos começou a ser substituído pelo modelo toyotista, o qual passou a reinar triunfante na última década do século $\mathrm{XX}$, sem, contudo, superar completamente o modelo anterior. Como lembra Best (1990), o próprio modelo fordista teve relação semelhante com o American system of manufacturing do século XIX, o qual, por sua vez, suplantara o modelo original da revolução industrial inglesa.

A administração é uma área na qual são freqüentes os modismos. Mas a verdade é que a prática da administração muda rápido. Novos paradigmas de prática se difundem e se modificam ao se difundirem, assim como se interpenetram e influenciam mutuamente. As reflexões teóricas sobre cada um deles rapidamente são assimiladas pelos praticantes e consultores e convertidas em novas práticas, alterando ainda mais o objeto de estudo.8

É por isso que em administração existe a distinção entre pesquisa descritiva e prescritiva. Trata-se de distinção impensável na ciência natural. A ninguém ocorreria ditar o comportamento de um elétron. Mesmo o engenheiro, submete-se à lógica causal do comportamento do elétron. Em administração, de outro modo, há uma dialética constante entre descrição, explicação e prescrição - a dupla hermenêutica de Giddens.

As práticas administrativas podem mudar por erro, mas também podem mudar por inovação deliberada. Nesse caso, aparecem os critérios de eficiência e eficácia sempre invocados na literatura administrativa. O desafio do administrador é garantir a reprodução das práticas eficazes e eficientes e, ao mesmo tempo, descartar práticas ineficazes e ineficientes, adotando novas práticas, inovadoras, que o uso indicará se eficazes e eficientes.

\section{A axiologia real da prática administrativa}

Em sua XI tese contra Feurbach, Marx e Engels (1977, p.14) propõem que "Os filósofos se limitaram a interpretar o mundo de diferentes maneiras; o que importa é transformá-lo". Popper (1987) opõe-se à revolução como método geral na mudança social, ${ }^{9}$ e recomenda um programa de reforma institucional gradual. Assim, concorda com Marx que a finalidade do estudo da sociedade é propor a mudança.

No caso da prática administrativa, o tema sequer está sujeito a dissenso. Todos concordam que a reflexão do praticante e a pesquisa científica a seu respeito obedecem ao mandato de transformá-la, o que coloca um horizonte radicalmente diferente da postura científica usual. A concepção clássica da ciência é a de contemplação, descrição e explicação de um objeto imune à ação humana.

$\mathrm{Na}$ administração, a contemplação é da própria prática dos administradores e não de um objeto imune às tentativas de entendimento pelo homem. A prática administrativa se altera conforme cresce o conhecimento a seu respeito. Mesmo que pesquisadores isolados possam apegar-se ao ideal do conhecimento contemplativo, 
praticantes e cientistas aplicados fazem parte do próprio ambiente social do qual o pesquisador platônico faz seu objeto de estudo. Praticantes lêem as revistas e livros dos pesquisadores e estudam em escolas onde são professores. E há até praticantes reflexivos e pesquisadores praticantes! Tais idéias impõem uma concepção crítica da pesquisa na administração, e ela sempre implica mudança potencial da prática. Então, a questão que se põe é mudar a prática para quê? Há três respostas.

- a solução conservadora - mudar para aumentar o controle do administrador;

- a solução revolucionária - mudar para aumentar a autonomia do administrado; ou

- mudar para aumentar a eficiência e eficácia da ação humana coletiva.

Neste terceiro sentido, desloca-se o eixo de questionamento. A maior ou menor autonomia do administrado seria meio para maior eficácia e eficiência. ${ }^{10} \mathrm{O}$ importante seria resolver conflitos e organizar a ação de modo a aumentar os frutos do trabalho cooperativo. Em particular, a prática administrativa, pelo seu papel na organização, voltar-se-ia para a regulação funcional da ação coletiva ou para a mudança controlada.

Na teoria da sociedade, segundo Burrel e Morgan (1979, cap.2), há oposição paradigmática, irreconciliável, entre as perspectivas da regulação e da mudança radical. No entanto, uma filosofia da prática permite uma visão do problema em que a tendência à regulação pode ser satisfeita por determinadas práticas, enquanto outras podem apontar na direção da mudança controlada ou radical. Em decorrência, cabe aqui frisar que, do ponto de vista do dirigente, a terceira formulação vale mesmo para partidos revolucionários!

Ao discutir o que fazer no movimento comunista, Lênin (1978) formula uma teoria do partido revolucionário como um partido de quadros altamente qualificados, com um mecanismo decisório e de ação, o centralismo democrático, capaz de atuar em circunstâncias de perseguição política dura, com a finalidade de derrubar a monarquia russa e implantar a ditadura do proletariado. Ora, embora sua missão para o partido seja revolucionária, sua ordem interna para ele é altamente hierárquica, com modo compulsório de operação. É a ordem do centralismo democrático. A missão é a agitação das massas contra a repressão do czar. Eficácia é o conceito central na estruturação e operação do partido! Eficiência, o uso cuidadoso e a preparação dos recursos - no caso, humanos -, é o segundo critério fundamental!

Quando Gramsci discorre sobre o partido comunista na Itália, percebe a importância da hegemonia ideológica e reconcebe o partido como organização não mais de quadros, mas de massa. A missão mudou, logo, a atuação eficaz e eficiente exige novos membros, nova organização e nova prática de direção. De novo, eficácia e eficiência! E embora haja uma distância radical entre um partido de massas e um partido leninista, no que se refere à organização e direção, em ambos a prática busca a conservação ou, no máximo, a mudança controlada.

Apenas em circunstâncias excepcionais, os dirigentes podem se dedicar à mudança radical da própria organização. Normalmente, só quando ocorrem mudanças drásticas no ambiente que tornam imperativas tais mudanças radicais. Mesmo assim, nessas ocasiões, é freqüente as organizações perderem o controle da mudança, dividirem-se ou sucumbirem, sem que consigam efetivar mudanças radicas.

As práticas administrativas podem visar tanto à regulação funcional quanto à mudança controlada da organização, ${ }^{11}$ mesmo nas mãos de quem deseja a mudança radical. Porém, se a mudança for descontrolada, não se alcançam os objetivos emancipadores dos seus proponentes! Há, por essa via, um interesse comum na eficácia e eficiência da prática administrativa. Certamente, eram centrais para Taylor, Fayol e Barnard.

Os critérios de eficiência e eficácia das práticas administrativas colocam um referencial claro de progresso na administração. Lembra Popper (1978a, p.84) ser possível estabelecer um critério claro de progresso em ciência, com a idéia de que as novas teorias devem "preservar o sucesso de suas predecessoras". Aron (2002, p.63) frisa que é fácil ver o progresso material na economia. O progresso econômico é evidente na constatação da crescente variedade e quantidade de bens à disposição da sociedade e na crescente divisão social e organizacional do trabalho. Aqui se pode ver a noção de progresso aplicada à administração, através dos critérios de eficiência e eficácia crescentes. Portanto, eficiência e eficácia são conceitos reguladores da 
aplicação da noção de prática administrativa, da mesma forma que Popper (1978a) entende a noção de verdade como reguladora do progresso científico. Essas noções emprestam objetividade à substituição das práticas administrativas, embora possam, muitas vezes, ser de difícil aplicação prática. Seu uso regulador, de modo análogo ao uso da noção de verdade em Popper, visa descartar o mau desempenho e tentar ampliá-lo com novas práticas.

Em cada pesquisa, assim como em cada prática administrativa, a opção axiológica fica implícita. Entretanto, como a prática poderá ser modificada, cabe ao cientista refletir sobre para onde apontam os resultados em cada caso. Ao apontar as implicações gerenciais de sua pesquisa, o pesquisador oferece a sua visão axiológica de seus resultados. Como sempre em ciência, seus críticos podem vê-los de outra perspectiva valorativa.

Pode-se ter certeza que a axiologia da administração e de sua pesquisa é uma axiologia de resultados e que faz parte do objeto de estudo. Práticas administrativas que não levam aos objetivos almejados ou o fazem com desperdício de recursos são logo descartadas pelos administradores em favor de outras mais eficazes e eficientes. Assim, as práticas originais desaparecem do objeto de estudos do pesquisador.

\section{Objetivos e resultados organizacionais}

Barnard (1942, p.73) define organização formal como “ um sistema de atividades ou forces conscientemente coordenadas de duas ou mais pessoas" 12 . Enfatiza-se aqui o caráter deliberado da organização. Por definição, a organização seria criada e mantida de modo deliberado por, pelo menos, parte de seus participantes. Barnard (1942, p.82) também sugere que "uma organização nasce quando (1) existem pessoas capazes de se comunicar, (2) que se dispõem a contribuir com atividades para (3) realizar um objetivo comum"13. Será que se pode falar de finalidades organizacionais? Serão propósitos comuns, como sugere Barnard?

Tendo em vista o questionamento da possibilidade das organizações terem propósitos, Mintzberg (1983, cap.2) dedica um capítulo de seu livro Power In and around organizations a uma revisão da literatura sobre o propósito das organizações. O autor (Ibid., p.246-247) conclui que as organizações têm sim propósitos que podem ser vistos em pelo menos quatro casos claros: quando há uma ideologia dominante, pela qual os membros de uma organização partilham um conjunto de crenças; quando um ator dominante impõe seus objetivos à organização, obtendo a cooperação dos demais participantes; quando um grupo de indivíduos tem objetivos comuns e criam ou se juntam a uma organização para facilitar a perseguição desses objetivos; ou quando a simples existência da organização beneficia seus membros. Nesse último caso, surgem os objetivos chamados de sistêmicos pelo autor: a sobrevivência da organização, certo nível de eficiência para assegurar essa sobrevivência, independência em relação a terceiros e, mais importante dentre estes, crescimento.

Mintzberg também deixa claro que os objetivos da organização não precisam ser integralmente comuns aos seus membros e que freqüentemente são objeto de disputa, somente ficando estabelecidos quando uma coalizão dominante consegue determiná-los. E quanto aos demais membros, fora da coalizão dominante? Resta-lhes submeter-se, sair ou serem excluídos da organização, ou receber incentivos para ficar e contribuir com seu trabalho. Para os dissidentes, há também a opção de submeterem-se, dissimulando a divergência, temporariamente, no aguardo de oportunidades para alterarem os objetivos organizacionais de que discordam.

Mintzberg lembra ainda que a disputa sobre os objetivos pode levar a organização à paralisação, à atuação inconsistente e ineficaz e até a sua dissolução. Isso caracteriza uma situação instável, que tende a ser superada pela ascensão de uma coalizão dominante. Assim, enfatiza-se que objetivos organizacionais são meios para a ação coletiva eficaz e eficiente. O que o objetivo faz é apenas formalizar os resultados da ação coletiva que a coalizão dominante elegeu como alvo. Em termos de pensamento, trata-se de um objetivo. Em termos de ação, trata-se de resultados. Os resultados esperados são cobrados dos administradores.

O ponto central, aqui, está em que as práticas administrativas ganham sentido no contexto dos objetivos organizacionais. São concebidas e justificadas em função de tais objetivos. Contudo, tais objetivos não são apenas idéias na mente do administrador, são a explicitação dos resultados esperados pela coalizão dominante 
da organização, suas expectativas. Portanto, têm existência real e independente da vontade do administrador e seus subordinados; ${ }^{14}$ tão real que sistemas e metodologias como administração por objetivos e sistemas de indicadores foram criados para aferir o alcance dos objetivos pela organização e seus membros.

\section{A lógica da situação do administrador}

O indivíduo precisa querer para tornar-se administrador de uma organização. Entretanto, o administrador não opera num vácuo. Ao contrário, como mencionado na nossa definição de prática, ele atua num contexto, como parte de uma organização. Se alguém opta por participar da organização, passa a ser cobrado pelas atividades e resultados sob sua responsabilidade. Tem a liberdade pessoal de agir em desacordo com o ambiente organizacional, mas arca com as conseqüências disso. Pode perder as posições de comando e promoções e até ser demitido por terceiros que monitoram e esperam resultados de suas ações.

A rede estruturada de relações sociais que chamamos de organização coloca de modo muito claro as responsabilidades e obrigações do administrador, ou seja, deixa claro a quem ele deve satisfação e delimita essas responsabilidades dentro de um quadro institucional e legal nítido. A conformidade não é apenas voluntária. Cada interlocutor espera e cobra resultados do administrador e aplica sanções e incentivos. Assim, essa rede estruturada de relações sociais regra e orienta o comportamento do indivíduo que administra.

A atenção do administrador em relação às cobranças é hierárquica e modificada pelas pressões momentâneas. No topo da hierarquia estão as exigências e responsabilidades do cargo ocupado. Sem dar suficiente atenção a essas responsabilidades, o administrador perde o cargo, o que pressiona em favor da conformidade.

Para garantir os resultados e promover a ação coletiva organizada, o administrador dispõe de um cardápio de rotinas administrativas e de solução de problemas e tomada de decisões (MARCH; SIMON, 1958). O cardápio de rotinas inclui o dar início a outras rotinas administrativas executadas por terceiros, ocupantes de outros cargos. Neste caso, o administrador converte-se em fonte de pressões para a execução das rotinas sob a responsabilidade de outro administrador ou funcionário.

É essa rede de relações sociais, organizacionais, de mercado e legais, entre outras, que assegura o sentido objetivo e o uso pelo administrador dos conceitos de eficácia e eficiência. Afinal, para subsistir, a organização precisa ser eficaz: gerar, pelo menos, os recursos que seus instituidores e participantes requerem para produzir e oferecer seus serviços. E como esse equilíbrio permanente é instável, na prática, a organização precisa acumular recursos e crescer.

Como diria Popper (1978b, 1979), há uma lógica da situação organizacional e social que cerca o administrador e lhe impõe responsabilidades e obrigações. Essa situação tem elementos estruturais que representam grande parte das premissas das decisões e da ação (SIMON, 1976) dos administradores..$^{15}$ O primeiro elemento dessa lógica é os objetivos e missões organizacionais. O cumprimento das missões e o alcance dos objetivos exigem atividades e recursos, que ao longo do tempo vão originando um sistema de práticas administrativas e operacionais. Nos casos relevantes, o funcionamento desse sistema de práticas exige uma divisão de trabalho e hierarquia nas organizações. Os resultados da aplicação das práticas ao agir coletivo são avaliados e cobrados numa divisão de trabalho e hierarquia, considerando os objetivos e missões. Por essa via, o administrador encontra suas responsabilidades.

\section{Divisão do trabalho e hierarquia}

Nas sociedades contemporâneas, de profunda divisão social do trabalho, cada indivíduo vive enredado numa teia de relações sociais de caráter econômico. Tais relações envolvem relações de troca e consumo, de propriedade e produção e de comando e subordinação. É imperativo participar da atividade econômica para ser titular de uma renda. 
Para Marx (1980), as relações sociais de produção são necessárias. ${ }^{16}$ Tais relações decorrem da divisão do trabalho. A cada nova prática produtiva ou instrumento produtivo, aparece uma nova divisão horizontal do trabalho. Acompanhando a divisão horizontal do trabalho, surge uma divisão vertical do trabalho. Sem ela não é possível a coordenação que o bom desempenho das tarefas produtivas exige, particularmente, quando a eficácia exige articulação de complexas seqüências de ações que recorrem a um instrumental sofisticado e pessoal treinado.

Essa hierarquia não se limita ao aspecto técnico da organização do trabalho. Há aqui uma rede imensa de relações sociais. Conforme os meios necessários para o exercício das atividades se tornam mais caros e especializados, eles se convertem em aspecto essencial. Terra, máquinas, equipamentos, insumos, dinheiro etc. são essenciais para a produção. Alguém tem de fornecer o capital. Sem isso, não há atividade produtiva. Os controladores do capital controlam as organizações e podem delegar o poder de mando. Quem cede o capital espera paga por isso. De novo, a necessidade de capital põe o negócio e seus administradores no seio de ampla rede de relações sociais. Por outro lado, o capital é inerte. Não faz nada sozinho. Alguém precisa colocar o capital em funcionamento. Essa é a missão dos recursos humanos. Recrutar e manter mobilizada essa base de recursos humanos tece nova teia de relações sociais. Recursos humanos são despesas. Para se converterem em receita é preciso um fluxo de transações e um modelo de negócios que forneça esse fluxo. De novo, a receita vem dos clientes e usuários ou de terceiros dispostos a sustentar as atividades. Mais relações sociais. Em toda essa teia de relações sociais que cercam a produção há ainda necessidade de informação (vem de mais relações sociais) e conhecimento técnico e gerencial.

Resumindo, dinheiro, conhecimento, informação e relações privilegiadas com determinados grupos, entre outros elementos, são vitais para o bom desempenho da produção nas modernas sociedades industriais. Obviamente, tais recursos e competências se tornam cruciais para administrar organizações e são aperfeiçoados na medida em que alguém as administra. Quem a isso se dedica, com o tempo, desenvolve melhor desempenho. Assim reforçam-se as hierarquias de produção de bens e serviços.

Uma ressalva importante, devida à escola sociotécnica de administração, é que a divisão de trabalho e a hierarquia admitem alternativas. Dada uma missão, não é única a organização capaz de realizá-la. Tampouco é equivalente o desempenho das diversas organizações possíveis num caso concreto. Diferentes organizações, com diferentes práticas, hierarquia e regras, podem ter desempenho muito diferente no cumprimento de uma mesma missão. Além disso, nada garante que os resultados sejam equivalentes para todos os interessados. Organizações distintas para uma mesma missão têm efeitos diferenciados para proprietários, administradores, empregados, clientes etc. Há muito espaço para conflito de interesses nesse processo de definição da organização.

Mas não são apenas as empresas capitalistas que exibem hierarquia. Cooperativas e fundações também requerem essa extensa rede de relações sociais e hierarquia. Há ainda outras finalidades de atividade coletiva que também exigem organização e hierarquia. Historicamente, muitas hierarquias até precederam as empresas capitalistas. Forças militares, polícias, igrejas, organizações sociais e instituições públicas, todas têm divisão de trabalho e hierarquia. É importante frisar aqui que tais hierarquias têm existência objetiva, independente dos indivíduos. Podem até ser frágeis e, subitamente, a organização e a hierarquia se desfazerem no ar. Isso acontece, por exemplo, quando um exército derrotado entra em fuga desordenada, quando uma empresa vem a falir ou quando uma religião se desmoraliza. Entretanto, isso não lhes retira a solidez que nelas vêem os indivíduos enquanto delas participam.

Para este artigo, importa frisar que a teia de relações sociais gera posições nas organizações. São papéis sociais dos quais se espera certas ações e reações quando provocados pelos estímulos característicos das relações sociais subjacentes. No exercício de tais papéis, os indivíduos são regidos por fortes regimes de responsabilidade. Essa responsabilidade, cobrada por terceiros, tem critérios objetivos, a saber: os objetivos organizacionais e inúmeros outros critérios formais e informais, tais como não matar as pessoas de modo arbitrário ou manter banheiros separados para homens e mulheres. 


\section{As responsabilidades do administrador}

Como lembra Weber (2004, p.30), o que caracteriza uma associação de empresa é a presença de um dirigente e um quadro administrativo que a representa e assegura o cumprimento dos seus estatutos.

As razões subjetivas porque tais quadros administrativos perseguem os objetivos organizacionais podem ter influência sobre a eficiência e eficácia desses quadros. Mas, há razões objetivas para que os dirigentes persigam os objetivos organizacionais. Suas posições integram uma teia de relações sociais objetivas, das quais não podem escapar. Empregados pedem recompensa. Clientes, serviço. Fornecedores, pagamento. Investidores, lucro. Terceiros afetados, compensações. Chefes, resultados. Governantes, obediência à lei. Essa teia de relações sociais que cerca o administrador materializa o conjunto das restrições e cobranças sociais que o ambiente organizacional e social coloca para a sua prática. Na sua intenção, ele pode qualquer coisa. Na prática administrativa, as demandas sobre o seu comportamento são múltiplas e variadas e ele não pode ignorá-las.

Convém lembrar que todos os interlocutores do administrador têm meios reais para cobrar os resultados que desejam da organização. Entra aqui um ponto básico na prática administrativa: a responsabilidade do praticante. A prática administrativa coloca o administrador no centro de uma teia de relações sociais de responsabilidades com os agentes envolvidos com a organização. Mintzberg (1980, p.50) sugere que essa situação tende "a

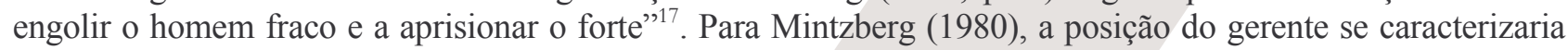
por estar "entre sua organização e uma rede de contatos"18 e por ser uma "composição de direitos e obrigações" "19. Quanto à doença ocupacional dos executivos, o estresse, apenas confirma a objetividade dessa situação.

Empregados rebelados, acionistas e clientes insatisfeitos, fornecedores mal pagos, leis descumpridas etc., todos representam limites ao poder e às ações do administrador, que deve incorporar tais limites em suas práticas e intenções. A teia de responsabilidades é objetiva para o administrador, pelo menos, enquanto pretender ficar no cargo ou, se não puder ser substituído, até o limite em que leve ao fim da organização. Isso explica porque mesmo o principal executivo passa a maior parte do tempo reagindo (Mintzberg, 1980, p.50). Além disso, também fornece elementos decisivos para a interpretação objetiva da prática administrativa. A intenção do administrador não é apenas subjetiva, mas oferecer resultados que atendam às expectativas dos seus interlocutores em razão das responsabilidades da posição que ocupa. Seus objetivos não dependem apenas de sua vontade. Há acionistas, credores, controladores, clientes, empregados, fiscais, policiais, imprensa etc. postados à sua porta, cobrando resultados.

Por outro lado, as ações do administrador, particularmente as rotineiras ou típicas da prática profissional ou setorial, integram o repertório básico de práticas de que dispõe para suas decisões e ações. Embora possa inovar ocasionalmente, ou improvisar, por desconhecimento do modo de fazer as coisas, suas organizações e seus interlocutores continuamente cobram o modo correto de fazer as coisas naquele particular contexto organizacional, profissional ou de negócios. Ou seja, há incentivos e sanções para adotar o sistema de práticas administrativas da organização. Entre os incentivos, o mais importante é que os modos sancionados de agir não são questionados, nem enfrentam resistência ou dificuldade de autorização no uso dos recursos necessários. O que vale inclusive para o próprio tempo de trabalho do empregado, em geral, e do administrador, em particular.

É claro que a cobrança sobre os administradores de nível mais baixo pode dirigir-se diretamente ao seu desempenho no uso de práticas padrão. Entretanto, à medida que o indivíduo assume postos mais elevados na hierarquia, seu poder discricionário aumenta, até pela função de resolver os problemas fora da rotina. Sua liberdade de ação aumenta. Nesse caso, a cobrança se volta mais para os resultados do que para o uso de práticas bem aceitas.

$\mathrm{Na}$ verdade, não se cobra dele apenas o emprego de boas práticas. Para obter melhores resultados, também espera-se dele que modifique as práticas ou que adote ou crie novas práticas. Tendo em vista o desempenho, concede-se maior autonomia ao dirigente de nível mais elevado, permitindo-lhe modificar o sistema de práticas 
que o cerca. No entanto, espera-se dele ganhos de desempenho da organização, principalmente, em face da concorrência.

\section{0 sentido objetivo da prática administrativa}

A prática humana tem sentido. Há algo objetivo neste sentido? Ou ele é subjetivo?

A resposta a essa pergunta tem a ver com a regularidade das motivações e objetivos humanos e organizacionais e também com a regularidade das condições externas nas quais ocorrem. Pode-se supor a influência estatisticamente significativa de alguns fatores sobre as ações de muitos, se não de todos os atores, presentes na prática administrativa. Mais que isso, pode-se supor que tais fatores sugerirão alternativas de ação similares, exceto para agentes sofisticados que, vez por outra, criarão novas respostas. Além disso, muitas alternativas estão institucionalizadas. O ponto aqui é distinguir entre o que o sujeito pensaria, sozinho ou influenciado por outros, e o que ele pode fazer, sozinho ou com terceiros, nas reais condições vigentes.

Convém, portanto, enfatizar que entre as razões do sujeito estão interesses e motivos típicos, sistematicamente reforçados, resultantes da sua inserção numa sociedade e em grupos de referência, instituições e organizações, sem os quais o indivíduo não poderia existir. É a lógica física e social da situação (POPPER, 1964, p.147-152, 1978b). Quem desconsidera a lógica da situação, o faz por sua conta e corre o risco de insucesso. Não importa se o ator age de modo consciente, ou não. Pode, por exemplo, seguir um roteiro tradicional ou um hábito. O que interessa é se a ação é eficaz. Essa idéia de Popper retoma a noção de ação racional em relação a fins de Weber e lhe empresta um caráter objetivo, independente da vontade dos indivíduos. ${ }^{20}$

Além disso, como lembra Weber com sua noção de ação racional em relação a valores, decisões e comportamento dependem de normas e valores construídos no meio social e adotados pelo indivíduo, livre ou compulsoriamente. $\mathrm{Na}$ administração, os valores de referência são eficácia e eficiência, cujo efeito normativo decorre de inúmeros sistemas de cobranças sociais e da própria vontade do administrador de buscar as recompensas associadas.

Fica assim nítida a distinção entre um sentido subjetivo e um sentido objetivo das práticas administrativas. O primeiro refere-se ao que quer que possa estar na mente de um administrador que se vê compelido a uma decisão ou ação.

O sentido objetivo se refere às condicionantes da situação objetiva posta, que tem componentes materiais e relações sociais e organizacionais. Entre essas condicionantes estão questões técnicas da divisão e organização do trabalho e dos demais recursos necessários, o sistema de práticas administrativas e também os interesses e finalidades da organização, assim como normas e valores da sociedade que cerca a organização.

$\mathrm{Na}$ prática humana, as idéias se encontram com a realidade material e social que cerca o indivíduo, sendo testadas pela sua capacidade de guiar a ação e resolver os problemas de satisfação das necessidades e desejos humanos.

$\mathrm{Na}$ prática administrativa, dirigida ao controle da ação coletiva, toda essa argumentação se torna mais pertinente. A prática do administrador não é solipsismo arbitrário. Ela tem por sentido seu papel no sistema de práticas e hierarquia do qual faz parte no desempenho dos objetivos organizacionais para os quais é invocada.

O resumo do que foi dito até aqui é que, diferente dos animais que apenas sentem e agem, o homem também pensa para agir. Tem motivos e objetivos, e o sucesso na ação, ou o alcance de tais objetivos ou motivos, depende do respeito à lógica do sítio da ação. Ao agir para viver, o homem aproveita as possibilidades inerentes e enfrenta a oposição dessa realidade expressa na lógica material e social da situação. Assim, há um sentido objetivo da ação administrativa, que ultrapassa, domina e integra seu sentido subjetivo. Por isso, a prática administrativa não é inteligível sem menção às suas finalidades e funções no contexto organizacional, ou seja, à 
lógica objetiva da organização e de sua ação. Seu sentido é dado para os agentes no sistema de práticas e objetivos organizacionais.

\section{Implicações epistemológicas ou metodológicas}

Na prática administrativa, o sentido da prática tem realidade objetiva e faz parte do objeto de pesquisa. No lugar do objeto das ciências da natureza, inanimado e isolado do sujeito, entra a prática administrativa dotada de sentido social e organizacional objetivo, voltada para organizar, planejar, dirigir e controlar a prática coletiva organizada.

Pesquisar em administração é estudar a prática administrativa, dos outros e a própria, tanto como gerentes quanto como sujeitos gerenciados, procurando entender por que funciona e buscando oportunidades de aumentar-lhe a eficiência e eficácia em relação aos objetivos organizacionais postos. Eficácia e eficiência, ao lado da noção de verdade, têm assim caráter de idéias reguladoras do progresso na pesquisa em administração.

O sentido objetivo da prática administrativa deriva da lógica da sua situação profissional, que afeta igualmente qualquer indivíduo na mesma posição organizacional. O caráter processual e relacional das práticas administrativas leva à necessidade de reconstruir conceitualmente, de forma abstrata, o objeto de estudo, já que ele inexiste como coisa.. Mas, ao contrário do que muitos pensam, isso não significa subjetividade, pois é possível a interpretação objetiva em administração (NASCIMENTO, 2007). Ela se apóia no sentido objetivo da prática administrativa e na objetividade do contexto organizacional.

A epistemologia da pesquisa em administração é crítica das idéias e da prática. Novas práticas resultam do trabalho científico e são adotadas por administradores, alterando o objeto de pesquisa. Descrever, compreender e explicar as práticas administrativas é criar as condições para aperfeiçoá-las e mudar o objeto estudado. Estudar a prática administrativa envolve uma complexa dialética ${ }^{21}$ entre descrição de estruturas sociais e comportamentos e significados associados, explicações causais das suas relações sociais e organizacionais e condições materiais e a prescrição de novas práticas. Tal lógica é distinta da aplicável nas ciências da natureza.

Reconhecer a possibilidade de mudança das práticas compromete o pesquisador com livre arbítrio epistemológico (NASCIMENTO, 2006). Ao mesmo tempo, fundamenta a possibilidade do comportamento excepcional, fora da regularidade estabelecida pelo sentido objetivo. Isso obriga a pesquisa da prática administrativa a estar atenta às providências para garantir a exclusão do comportamento excepcional ou controlar seus impactos indesejados.

Com essa lógica da situação influenciando fortemente o administrador, a racionalidade instrumental predomina na prática administrativa e se converte em rotina profissional e organizacional. Por tudo aqui exposto, a praxiologia, ou filosofia da prática, representa um forte candidato a fundamento para a teoria da prática administrativa. 


\section{Referências}

ARON, R. As etapas do pensamento sociológico. Tradução: Sérgio Bath. São Paulo: Martins Fontes, 2002.

BARNARD, C. I. The functions of the executive. Cambridge, Massachusetts: Harvard University Press, 1942.

BEST, M. H. The new competition - institutions of industrial restructuring. Cambridge, Massachusetts: Polity Press, 1990.

BHASKAR, R. General introduction. In: ARCHER, M. et alii, (Ed.) Critical realism - essential readings. London: Routledge, 2004.

BOURDIEU, P 1983. Esboço de uma teoria da prática. Tradução de Paula Monteiro da parte "Les trois modes de connaissance" dans "Esquisse d'une theorie de la pratique". Em: Ortiz, R. Peirre Bourdieu. Coleção Sociologia (Coordenação: Florestan Fernandes). Editora Ática S. A. São Paulo. 1983. p. 46.

BURRELL, G.; MORGAN, G. Sociological paradigms and organizational analysis - elements of the sociology of corporate life. Brookfield, Vermont, USA: Ashgate Publishing Company, 1979. Reprinted in 1994.

COOK, S. D. N.; BROWN, J. S. Bridging epistemologies: the generation dance between organizational knowledge and organizational knowing. Organizational Science, v.10, n.4, p.381-400, July/Aug. 1999.

FAYOL, H. General and industrial management. London: Pitman, 1949.

GIDDENS, A. New rules of sociological method. 2nd ed. Stanford, California: Stanford University Press, 1993.

A constituição da sociedade. Tradução: Álvaro Cabral.São Paulo: Martins Fontes, 2003.

LENIN, V. I. Que fazer? São Paulo, SP: Editora Hucitec, 1978.

MARCH, J. G.; SIMON, H. A. Organizations. New York: John Wiley, 1958.

MARX, K. 018 de brumário de Luís Bonaparte. Portugal: Editorial Estampa, 1976. Tradução de Maria Flor Marques Simões, a partir da edição traduzida para o francês e publicada pelas Editions Sociales, Paris, 1948.

0 capital - crítica da economia política. 5.ed. Tradução: Reginaldo Sant'Anna. Rio de Janeiro: Civilização Brasileira, 1980.

; ENGELS, F. A ideologia alemã. Tradução: José Carlos Bruni e Marco Aurélio Nogueira. [S.I.]: Editorial Grijalbo. 1977.

MINGERS, J. The contribution of critical realism as an underpinning philosophy for OR/MS and systems. Journal of Operational Research Society, n.51, p.1256-1270, 2000.

MINTZBERG, H. The nature of managerial work. Englewood Cliffs, NJ, USA: Prentice Hall, Inc., 1980.

. Power in and around organizations. Englewood Cliffs, NJ: Prentice Hall Inc., 1983.

NASCIMENTO, P. T. S. O livre arbitrio epistemológico. Organização \& Sociedade, v.13, n.38, jul./set. 2006.

A interpretação objetiva em administração. In: XXXI Encontro da Associação Nacional de Pós-Graduação e Pesquisa em Administração, 2007, Rio de Janeiro. Anais... Rio de Janeiro: ANPAD, 2007. CD ROM.

NELSON, R. R.; WINTER, S. G. An evolutionary theory of economic change. The Belknap Press of Harvard University Press. Cambridge, Massachusetts, and London, England. 1982.

POPPER, K. R. The poverty of historicism. New York: Harper \&t Row Publishers, 1964.

A racionalidade das revoluções científicas. In: CHACON, V. (Org.). Lógica das ciências sociais. Tradução: Estevão de Rezende Martins, Apio Cláudio Moniz Aquarone Filho, Vilma de Oliveira Moraes e Silva. Edições Tempo Brasileiro. Rio de Janeiro. 1978.

Lógica das ciências sociais. In: CHACON, V. (Org.). Lógica das ciências sociais. Tradução: Estevão de Rezende Martins, Apio Cláudio Moniz Aquarone Filho, Vilma de Oliveira Moraes e Silva. Edições Tempo Brasileiro. Rio de Janeiro. 1978.

Objective knowledge - an evolutionary approach. Revised edition. Oxford: Oxford University Press, 1979. 
A sociedade aberta e seus inimigos. Tradução: Milton Amado.[S.I.]: Editora Itatiaia Ltda.; Editora da Universidade de São

Paulo, 1987.

Conjectures and refutations - the growth of scientific knowledge. London: Routledge, 2002.

PRADO JR. C. Introdução à lógica dialética. 4.ed. São Paulo: Editora Brasiliense, 1979.

RODRIGUES, J. A. (Org.) Durkheim. 9.ed. São Paulo, SP: Editora Ática, 2004. (Coleção Grandes Cientistas Sociais. Sociologia.).

RUSSEL, B. A History of Western philosophy. New York: Simon \& Shuster, 1945.

RUSSEL, B. História do Pensamento Ocidental - a Aventura das Idéias dos Pré-Socráticos a Wittgenstein. 5a. edição. Ediouro Publicações S. A. Rio de Janeiro e São Paulo. 2001.

SIMON, H. I. Administrative behavior. New York: The Free Press, 1976.

VAZQUEZ, A. S. Filosofia da práxis. 2.ed. Rio de Janeiro: Editora Paz e Terra, 1977.

VICO, G. A ciência nova. Tradução: Marco Lucchesi. Rio de Janeiro: Editora Record, 1999.

VILA NOVA, S. Introdução à sociologia. São Paulo, SP: Editora Atlas S.A., 1989.

WEBER, M. Economia e sociedade - fundamentos da sociologia compreensiva. Tradução: Regis Barbosa e Karen Elsabe Barbosa. São Paulo: Editora UnB; Imprensa Oficial do Estado de São Paulo, 2004.

ZYGMONT, J. Microchip - an idea, its genesis and the revolution it created. Cambridge, MA, USA: Perseus Publishing, 2003.

1 "social objects include beliefs about themselves".

${ }^{2}$ A pessoa não pode saltar do último andar de um prédio de 20 andares, nem, tampouco, passar muito tempo sem comer regularmente ou sem abrigo das intempéries.

${ }^{3}$ Por exemplo, o sujeito que precisa de atendimento médico, quando ferido ou doente, depende da cooperação de terceiros. Alguém só pode comprar, se aceitam the vender. Só se é entendido quando se fala a língua do interlocutor. Só há casamento se o amor é correspondido.

${ }^{4}$ Aqui, grupo está empregado genericamente. Refere-se tanto a categorias profissionais quanto a grupos confessionais ou a classes sociais, entre outros. Vila Nova (1989, parte III) trata da diversidade de grupos sociais.

5 "the coordinated activities of individuals and groups in doing their 'real work' as it is informed by a particular organizational or group context".

6 "Our general term for all regular and predictable behavioral patterns of firms is "routine". We use this term to include characteristics of firms that range from well specified technical routines for producing things, through procedures for hiring and firing, ordering new inventory, or stepping up production of items in high demand, to policies regarding investment, research and development (R\&D), or advertising, and business strategies about product diversification and overseas investment".

${ }^{7}$ É usual atribuir a Durkheim a coisificação dos fatos sociais. É verdade que o autor tende, por vezes, a confundir objetos e processos, mas nem de longe na extensão que the atribuem seus detratores. Ainda assim, citá-lo é uma forma compacta de referir-se ao trato das práticas como coisas e não como processos praticados por agentes.

${ }^{8}$ Não surpreende que metodologias qualitativas sejam constantemente invocadas para se entender o que está acontecendo de novo antes de serem aplicadas metodologias quantitativas para mensurar padrões e fenômenos.

${ }^{9}$ Que ele só aceita contra o totalitarismo.

${ }^{10}$ Modernamente, controle e engajamento são vitais para o alto desempenho na ação coletiva. Empregados conscientes e dispostos a contribuir tornam a organização mais eficaz e eficiente. A autonomia concedida aos membros da organização, que nas empresas sofisticadas podem ser até os próprios operadores, torna-se questão vital para o alto desempenho.

${ }^{11}$ Inclui-se aqui a mudança da missão da organização, sua morte ou sua divisão, originando organizações filhotes, subordinadas a (filiais) ou em conflito com (spin-off) a organização mãe. Um bom exemplo é o fenômeno dos spin-offs nas empresas de microchips quando surgiu a microeletrônica nos EUA. Zygmont (2003) conta essa história em seu livro sobre o tema.

12 "a system of consciously coordinated activities or forces of two or more persons ". Trata-se, é claro, de uma abstração. Análoga à noção de alavanca de Arquimedes, de gás perfeito da teoria cinética dos gases, de campo eletromagnético ou à de espécie, na biologia. Serve para deixar explícitas as propriedades relevantes do objeto isolado para estudo e para teorizar sobre uma concepção explícita. A teoria resultante deve submeter-se ao teste empírico. 
13 "an organization comes into being when (1) there are persons able to communicate with each other, (2) who are willing to contribute action, (3) to accomplish a common purpose".

${ }^{14}$ Isso não significa que os administradores não possam influenciar os objetivos da organização. Apenas não podem violá-los impunemente.

15 Simon (1976) foi o primeiro a colocar o papel da organização na tomada de decisão nesses termos. A racionalidade limitada do administrador ganha potência por que a sua inserção na organização coloca premissas às quais recorre regularmente. Sempre. Mesmo quando viola alguma delas, aceita as demais.

${ }^{16}$ Marx também propõe que as relações sociais de produção condicionariam todas as outras relações sociais. Mas alguém pode aceitar a impossibilidade dos atores sociais se isolarem das relações de produção e, ao mesmo tempo, negar a determinação da superestrutura social pela infra-estrutura econômica. Aliás, Aron (2002) sugere que os próprios conceitos de supra e infra-estruturas não estão muito claros em Marx.

17 "to swallow the weak man and to cage the strong one".

18 "between his organization and a network of contacts".

19 "blend of rights and duties".

${ }^{20}$ Aron (2002) lembra que Pareto faz distinção análoga quanto à a dicotomia entre ação lógica e não-lógica.

${ }^{21}$ Prado Jr. (1979) faz a distinção entre dialética da natureza e dialética como lógica do conhecimento, concedendo validade só a essa última. Neste trabalho, o tema é deixado deliberadamente em aberto. Aqui, o termo só é usado nas teses de caráter epistemológico, embora se possa argumentar que toda prática administrativa supõe conhecimento do praticante, tornando a dialética do conhecimento parte da própria realidade examinada. 